\title{
Studies on Mechanical, Thermal and Electrical Properties of Sugarcane Waste Filled HIPS (High Impact Poly Styrene)
}

\author{
S Soundararajan*, K Palanivelu and S K sharma \\ (Dept of Plastics Technology, Central Institute of Plastics Engineering and Technology Chennai-600 032, \\ India)
}

\begin{abstract}
HIPS (High Impact Polystyrene) was blended with sugarcane waste in three formulations: 10, 18 \& $25 w t \%$ using a twin screw extruder. Test specimens were prepared using an injection molding machine. Mechanical, thermal and electrical properties were determined. Flexural strength, hardness, VSP (Vicat softening point) were improved. The tensile strength, impact strength, volume resistivity were decreased. Also melt flow index was decreased. HIPS is photo-degradable and sugarcane waste is bio-degradable. Hence sugarcane waste filled HIPS will be photo/biodegradable. The sugarcane waste filled HIPS may be useful for disposable applications like cups, lids, trays, tubs, pens with lower cost.
\end{abstract}

Key Words: HIPS, Sugar cane waste, Twin screw compounding, Mechanical, \& Thermal properties.

\section{Introduction}

The Polystyrene is brittle [1] since it has higher $\mathrm{T}_{\mathrm{g}}$ (glass transition temperature) $105^{0} \mathrm{C}$. Hence Polystyrene is modified with rubber either polymerization in presence of Poly butadiene [2] or by blending with copolymers like SBR (styrene butadiene) or block copolymers such as SBS [3] (styrene butadiene styrene) to improve the impact strength of polystyrene. This is known as high impact polystyrene (HIPS). The izod impact strength (notched) of polystyrene is $0.25 \mathrm{ft}$.lb/in only. The HIPS has $0.60-4.5 \mathrm{ft}$.- $-\mathrm{b} / \mathrm{in}$.

HIPS resins are known for their ease of processing, good dimensional stability. high impact strength and rigidity. HIPS is widely used in the packaging and disposables like food packaging, food services, dairy containers, vending and portions cups, lids, plates and bowls [4]. Also useful as disposable pens, audio video cassettes, refrigerator liners, small appliances, consumer electronics, toys, recreations and flame retardant (FR) grade UL 94-Vo used in television cabinets and computer machine housings. HIPS with PPO as polymer blend is commercially available. HIPS improves the processability and toughness of PPO plastics. The PPO-HIPS blend is used as automotive body structures and appliance mixer bodies.

HIPS having poly butadiene, which provides higher, impact strength to polystyrene. The HIPS is being used in many disposable plastics applications like disposable pens, disposable cups and plates because the unsaturated poly butadiene is degradable in presence of sunlight, which possess UV light energy. Sugarcane waste is available in very large quantities from sugar mill industries, which is biodegradable due to presence of cellulosic units. Our interest in this study is to make HIPS products biodegradable apart from photo-degradable like HIPS with starch [5]. In this present study we have determined the mechanical, thermal and electrical properties of sugarcane waste filled HIPS.

\subsection{MATERIALS :}

\section{Experimental}

HIPS was obtained from Supreme Petrochemicals Ltd., Chennai. The sugarcane waste was obtained from a sugarcane waste was obtained from a sugarcane juice shop DOP (Dioctyl phthalate) was supplied by BDH Chemicals Company, Chennai, and used as a wetting/ dispersing agent of sugarcane waste powder to the HIPS granules while high speed mixing.

\subsection{METHODS}

TWIN SCREW COMPOUNDING

The sugarcane waste was crushed into small particles by a flour mill and then sieved through a particle size sieve analyzer. Particles about -20 micron were taken for blending with HIPS. The HIPS was mixed with DOP $(1 \%)$ in a high speed mixer. Then the sugarcane waste was added and mixed thoroughly with the HIPS. Then the mixture was used in a Twin Screw compounding extruder. The temperature profile was given below: 


\begin{tabular}{|l|c|c|c|c|c|}
\hline Zones & 1 & 2 & 3 & 4 & 5 \\
\hline Temperature $\left({ }^{0} \mathrm{C}\right)$ & 90 & 155 & 175 & 185 & 190 \\
\hline
\end{tabular}
\begin{tabular}{|l|c|c|c|c|c|}
\hline Zones & 6 & 7 & 8 & 9 & $10(\mathrm{Die})$ \\
\hline Temperature $\left({ }^{0} \mathrm{C}\right)$ & 195 & 200 & 205 & 205 & 210 \\
\hline
\end{tabular}

The extrudate was passed through a water cooling trough and then chopped into granules. Using the granules, test specimens were prepared.

\subsection{TEST SPECIMEN PREPARATION}

SP 130 injection molding machine. Test specimen like tensile strength, flexural strength, impact strength, VSP, Arc resistance, volume resistivity and surface resistivity. The test specimens were prepared as per ASTM standards using a Clackner Windsor injection molding M/c. (SP 130) These properties were measured using the ASTM Standards [6].

\subsection{TESTING}

The tensile strength \& elongation test was done using an UTM (Universal Testing Machine) Instron 1195 (U.K.) with test speed $50 \mathrm{~mm} / \mathrm{min}$. Type 1 test specimen of ASTM D638 standard was used. The flexural strength test was done using the same UTM M/c with the fixture for flexural test. The test specimen thickness was $3.2 \mathrm{~mm} \&$ the test speed was $1.4 \mathrm{~mm} / \mathrm{min}$. The impact strength izod (notched) was done using an ATS Faar (Italy). The test specimen was $63.5 \times 12.7 \times 3.2 \mathrm{~mm}$. The VSP (Vicat Softening Point) was done using a HDT/VSP equipment, Wallace (U.K.) $127 \times 12.7 \times 3.2 \mathrm{~mm}$ test specimen was used. The melt flow index test was tested using granules at $230^{\circ} \mathrm{C} / 2.16 \mathrm{~kg}$ load using Lloyd equipments (U.K.) The volume resistivity and surface resistivity tests were carried out as per ASTM D257 standard using Tero ohm meter (Ceast, Italy), The test specimen size is $110 \mathrm{~mm}$ dia $\mathrm{x} 3.2 \mathrm{~mm}$ thickness. Same test specimen was used for Arc resistance test as per ASTM D 495 using a high voltage low current equipment (Ceast, Italy).

\section{Result And Discussion}

The test results were tabulated in Table I \& II and also displayed in Figure I \& II.

\subsection{Mechanical Properties}

The tensile strength of the sugarcane waste filled HIPS, was slightly reduced (Table-I) \& (Figure 1). The elongation at break was also reduced. The flexural strength was increased. Also, the rock well hardness (Figure II) was increased. This trend is due to increase in rigidity of the sugarcane filled HIPS. Since, the sugarcane waste is grinded into particles, the sugarcane waste acts as particulate filler rather than fibre. Hence the impact strength is also reduced (Figure II). However this may be adequate for disposable application like cups, plates, pens, trays, tubs.

\begin{tabular}{|c|c|c|c|c|c|c|c|}
\hline \multirow{3}{*}{ Sl. No. } & \multirow{3}{*}{ Properties } & \multirow{3}{*}{$\begin{array}{l}\text { Test Method } \\
\text { ASTMD }\end{array}$} & \multirow{3}{*}{ Unit } & \multicolumn{4}{|c|}{ Test results } \\
\hline & & & & \multirow[b]{2}{*}{ HIPS } & \multicolumn{3}{|c|}{ Sugarcane Waste } \\
\hline & & & & & $10 \%$ & $18 \%$ & $25 \%$ \\
\hline 1. & Tensile Strength & 638 & $\mathrm{Kg} / \mathrm{cm}^{2}$ & 299.82 & 263.32 & 254.95 & 205.69 \\
\hline 2. & Elongation at break & 638 & $\%$ & 50 & 47 & 45 & 40 \\
\hline 3. & Flexural Strength & 790 & $\mathrm{Kg} / \mathrm{cm}^{2}$ & 536.61 & 542.55 & 565.01 & 567.11 \\
\hline 4. & Izod impact strength notched & 256 & $\mathrm{Kg} \mathrm{cm} / \mathrm{cm}$ & 13.02 & 9.46 & 7.63 & 7.26 \\
\hline 5. & Rockwell hardness & 785 & R-Scale & 90 & 92 & 93 & 94 \\
\hline
\end{tabular}

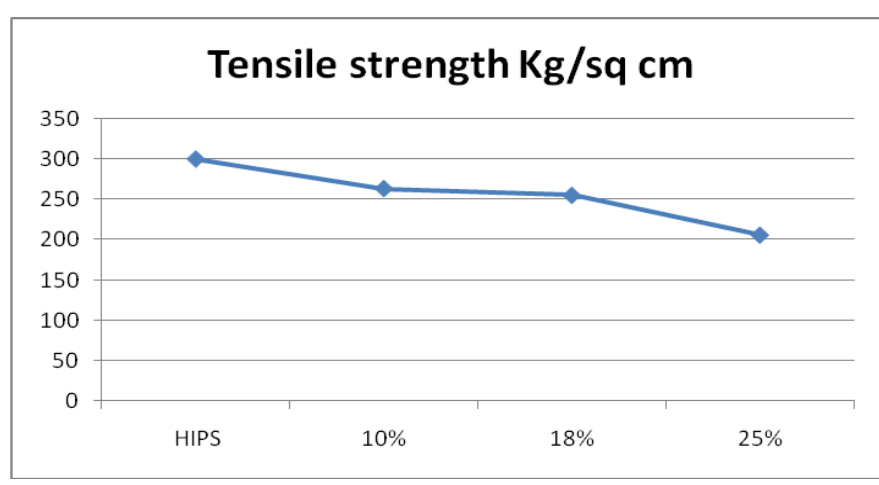

Figure 1. Tensile Strength of HIPS and $10 \%, 18 \%$ \& $25 \%$ Sugar cane waste Filled HIPS 


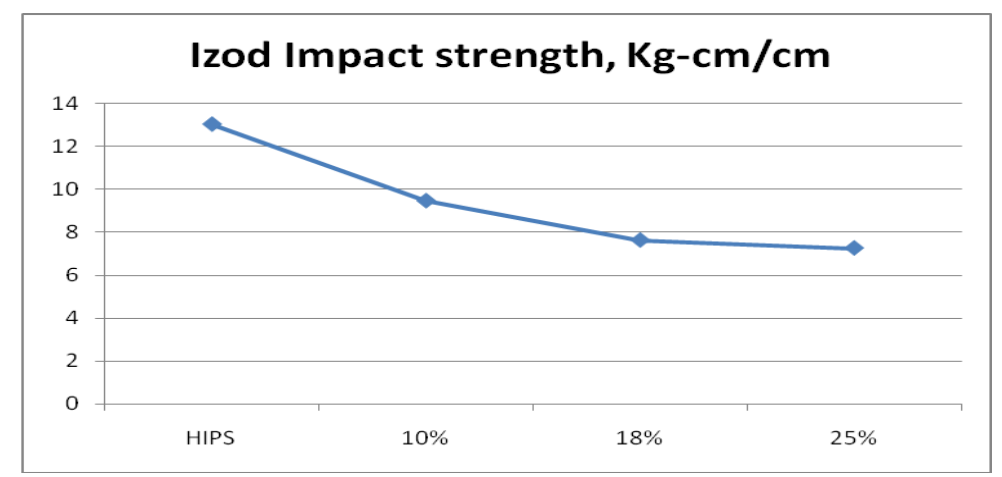

Figure 2. Impact Strength of HIPS and $10 \%, 18 \%$ \& $25 \%$ Sugar cane waste Filled HIPS

\subsection{Thermal properties}

The sugarcane waste is of higher molecular weight. Hence, hard, rigid brittle in characteristics. So, the VSP was increased. The melt flow index was decreasing (Table -II). The $25 \%$ sugarcane waste filled material is not at all flowing because the natural polymer cellulose has very higher molecular weight than HIPS.

\begin{tabular}{|c|l|c|c|c|c|c|c|}
\hline \multicolumn{2}{|c|}{ Table - II : Thermal, electrical \& physical properties of sugarcane waste filled HIPS } \\
\hline \multirow{2}{*}{$\begin{array}{c}\text { SI. } \\
\text { No. }\end{array}$} & \multicolumn{1}{|c|}{$\begin{array}{c}\text { Test } \\
\text { Pethod } \\
\text { ASTMD }\end{array}$} & \multirow{2}{*}{ Unit } & & \multicolumn{4}{|c|}{ Test results } \\
\cline { 5 - 8 } & & & HIPS & $\mathbf{1 0 \%}$ & $\mathbf{1 8 \%}$ & $\mathbf{2 5 \%}$ \\
\hline 1. & $\begin{array}{l}\text { Melt flow index at } \\
190^{\circ} \mathrm{C} / 2.16 \mathrm{Kg} .\end{array}$ & 1238 & $\mathrm{gms} / 10 \mathrm{mins}$ & 1.44 & 1.32 & 1.12 & Nil \\
\hline 2. & Vicat Softening Point & 1525 & ${ }^{0} \mathrm{C}$ & 102.70 & 102.10 & 101.10 & 97.7 \\
\hline 3. & Volume resistivity & 257 & $\begin{array}{c}\text { Ohm cm } \\
\text { x } 10^{11}\end{array}$ & 1.89 & 1.60 & 1.48 & 1.43 \\
\hline 4. & Surface resistivity & 257 & Ohmx $10^{11}$ & 2.57 & 2.36 & 2.18 & 1.93 \\
\hline 5. & Arc resistance & 495 & Seconds & 157 & 153 & 150 & 143 \\
\hline 6. & Specific gravity & 792 & & 1.02 & 1.04 & 1.06 & 1.067 \\
\hline
\end{tabular}

\subsection{Electrical Properties}

The sugarcane waste being polar in nature due to cellulosic units and hence it absorbs moisture. So, the electrical properties like volume resistivity and surface resistivity were lowering (Table-II) as the sugarcane waste percentage was increasing. Also the Arc resistance was decreasing.

\subsection{Degradability}

HIPS is photo degradable and the cellulosic units of sugarcane waste is biodegradable. After photo degradation of HIPS, the lower molecular weight HIPS fragments will be bio-degradable. The micro-organisms will consume these fragments and as well as the sugarcane waste molecules. No residue will be left in the environment. Hence the photo/biodegradable HIPS - Sugarcane waste plastics products will be eco-friendly.

\section{Conclusion}

It was found that, flexural strength, rock well hardness, VSP and specific gravity were found to be increasing, while tensile strength, impact strength, arc resistance, volume resistivity and surface resistivity were decreasing. Also, the MFI, (Melt flow index) was decreasing. The 25\% sugarcane waste filled has no flow at all. For disposable applications like cups, plates, pens, trays and tubs the impact strength may be adequate. Due to the blending of sugarcane waste with HIPS the cost can be lowered. HIPS is photodegradable and the sugarcane waste is bio-degradable. Hence, sugarcane waste filled HIPS will be photo/bio-degradable.

\section{References}

[1]. J.A. Brydson, Plastics Materials, Butterworth Heinmann 1999, $7^{\text {th }}$ Edition, P.437

[2]. Richard Reena, Modern Plastics, Mid-October 1992, p.91

[3]. J.A. Brydson, Plastics Materials, Butterworth Heinmann 1999, $7^{\text {th }}$ Edition, P.440

[4]. Richard Reena, Modern Plastics, Mid-October 1992, p.92.

[5]. J Subburaj and S Soundararajan, "Effect of Starch on Mechanical, Electrical, Physical ,Thermal properties and Photo/BioDegradation of HIPS-Starch blend"IOSR-Journal of Applied Chemistry, 1(2), 2012, 01-09

[6]. Annual ASTM Standards, 08.01-0.2, USA, 2000 